\title{
LL-37 but Not 25-Hydroxy-Vitamin D Serum Level Correlates with Healing of Venous Leg Ulcers
}

\author{
Alicja Krejner ${ }^{1}$ Małgorzata Litwiniuk ${ }^{1,2,3} \cdot$ Tomasz Grzela $^{1,4}$
}

Received: 1 January 2016/Accepted: 10 June 2016/Published online: 23 September 2016

(c) The Author(s) 2016. This article is published with open access at Springerlink.com

\begin{abstract}
Human cathelicidin, LL-37, is small antimicrobial peptide, which reveals also some immunomodulatory and proangiogenic properties and, therefore, may promote wound healing. The expression of LL-37 is controlled by various factors, including vitamin $\mathrm{D}$. Thus, any disturbances in vitamin D level may influence LL-37 production and, possibly, affect wound healing. Since deficiency of vitamin $\mathrm{D}$ was identified as a common problem in the population, this proof of concept study aimed to verify the relationship between serum levels of LL-37, vitamin D, and healing rate of venous leg ulcers. The study involved small group $(n=19)$ of patients with venous leg ulcers. Apart from non-venous ulcer aethiology, compression intolerance, active vein thrombosis, and wound infection, the exclusion criteria concerned also kidney insufficiency. The results of the analysis of wound healing rates were correlated with patients' serum levels of $25(\mathrm{OH})$ vitamin D and LL-37. In addition, serum levels of pro-inflammatory cytokines (IL-6, IL-8, and TNF) were analyzed. We have found strong association between serum concentrations of LL-37 and the healing rates in patients with leg ulcers. Despite the fact that $25(\mathrm{OH})$ vitamin D levels in all patients
\end{abstract}

Tomasz Grzela

tomekgrzela@gmail.com

1 Laboratory of Cell Molecular Biology, Department of Histology and Embryology, Biostructure Research Centre, Medical University of Warsaw, Chalubinskiego 5, 02-004 Warsaw, Poland

2 Postgraduate School of Molecular Medicine, Medical University of Warsaw, Warsaw, Poland

3 Department of Otolaryngology, Medical University of Warsaw, Warsaw, Poland

4 Clinic of Phlebology, Warsaw, Poland were below the normal range, they did not show any correlation with healing rates. Furthermore, no association was observed between serum levels of $25(\mathrm{OH})$ vitamin $\mathrm{D}$ and LL-37. No significant correlation between tested proinflammatory cytokines and healing rate, LL-37, or $25(\mathrm{OH})$ vitamin D levels was also observed. Regardless of small study group, our results suggest that the assessment of serum concentration of LL-37, but not 25-hydroxy vitamin $\mathrm{D}$, may help in predicting the wound healing efficacy. Moreover, this assessment may be useful in pre-selection of patients, which could benefit from local treatment with exogenous LL-37.

Keywords Cathelicidin - Healing rate - LL-37 . Venous leg ulcer · Vitamin D

\section{Introduction}

The standard treatment of venous leg ulcer comprises the use of compression therapy and proper local wound management. The compression allows the significant reduction of chronic venous hypertension in affected leg and thus improves the local blood perfusion (Partsch and Mortimer 2015). The local wound care, due to the use of various technologically advanced dressings, provides optimal conditions for tissue regeneration in the wound bed (Krejner and Grzela 2015; Waring and Parsons 2001). In majority of patients, this standard approach is sufficient enough to get good results. However, in some cases, despite the combination of effective compression and adequate local treatment, the wound healing is not satisfactory. Several detrimental factors were identified until now, including bacterial colonization of the wound, persisting chronic inflammation, or excess of destructive 
matrix metalloproteinases (Litwiniuk et al. 2009; Mustoe et al. 2006). However, delay in the wound healing may also be due to some other, so far superficially defined parameters, including genetic predisposition or metabolic state of the organism (Banerjee and Sen 2015; Shaw and Martin 2009; Weinstein et al. 2015). The last condition is highly sensitive to generalized malnutrition, or selective deficiency of particular agent. One of good examples of such agent could be vitamin D (Burkiewicz et al. 2012a, b; Zubair et al. 2013), especially since its deficiency was recently recognized as the common problem in the elderly population, who constitute the vast majority of patients with non-healing wounds (Houston et al. 2015).

Apart from its well known role in regulation of calciumphosphate homeostasis, vitamin D was found to reveal some other activities, including regulation of immune response (Hewison 2012; Tiwari et al. 2014; Trochoutsou et al. 2015). One of postulated modes of vitamin D action in immunity could be regulation of expression of small cationic antimicrobial peptides, among them human cathelicidin (Doss et al. 2010; Gonzalez-Curiel et al. 2014; Grzela et al. 2012).

Human cathelicidin is synthesized by numerous cells as an inactive precursor, hCAP18/LL-37. It consists of a highly conserved $\mathrm{N}$-terminal signal sequence, a conserved cathelin domain, and small antimicrobial C-terminal domain, known as LL-37 (Vandamme et al. 2012). Proteolytic cleavage of the hCAP18/LL-37 precursor leads to the release of antimicrobial LL-37 domain. This domain exhibits direct antimicrobial and anti-biofilm effect on a broad spectrum of Gram-positive and Gram-negative bacteria, viruses, and fungi (Barlow et al. 2011; Overhage et al. 2008; Wong et al. 2011). Besides its direct bactericidal activity, human cathelicidin can also reveal some indirect antimicrobial effects. It may attract various cells of the innate immune system to deal with pathogens; furthermore, it can influence the production and secretion of several pro- and anti-inflammatory cytokines. Thus, LL-37 may modify the inflammatory response (Agier et al. 2015; Wuerth and Hancock 2011). Interestingly, it was also recognized as regulator of angiogenesis and re-epithelialization (Heilborn et al. 2003; Koczulla et al. 2003). Therefore, due to its pleiotropic mode of action, LL-37 may be important for the healing of chronic wounds, including those infected with multiple, and biofilm-forming organisms (Ammons 2010).

The expression of hCAP18/LL-37 is controlled by various factors. Since the promoter region of the cathelicidin gene contains a vitamin D response element, also, the already mentioned vitamin D may play important role in that regulation (Gombart et al. 2005). It has been reported that in healthy adults, serum levels of LL-37 positively correlated with vitamin $\mathrm{D}$ concentrations
(Dixon et al. 2012). On the other hand, vitamin D deficiency was suggested to impair the immune response (Gombart 2009). These observations may be of great clinical importance, due to previously mentioned common deficiency of vitamin D (Houston et al. 2015). Therefore, the aim of our proof of concept study was to verify the possible relationship between serum concentrations of vitamin D, human cathelicidin LL-37, and the healing of chronic venous leg ulcers. Considering the context of chronic inflammation associated with leg ulcers, to enable easier analysis of collected data, serum levels of pro-inflammatory cytokines [interleukin (IL)-6, IL-8, and tumor necrosis factor (TNF)] were also measured.

\section{Materials and Methods}

The study involved 19 patients (12 female and 7 male and mean age $68.6 \pm 13.8$ ) with chronic venous leg ulcers present for at least 8 weeks, but not longer than 2 years. The venous insufficiency etiology of assessed wounds was confirmed by Duplex-Doppler ultrasound examination. The exclusion criteria involved clinical symptoms of wound infection within last 4 weeks preceding the assessment, arterial insufficiency with ankle-brachial pressure index $<0.8$ or $>1.1$, active deep vein thrombosis, clinically significant kidney insufficiency as well as any systemic disease in unstable stage. All patients received local wound management according to TIME (tissue-inflammation-moisture edges) strategy and recommendations of multidisciplinary expert group from Polish Wound Management Society (Jawień et al. 2011). The wound was covered by the hydrofiber-foam composite dressing (Aquacel Foam, ConvaTec, Deeside, UK), and multilayer compression was applied to the affected leg. All patients gave the informed consent to participate in the study that was approved by the local ethics committee and conducted according to ethical guidelines of the 1975 Declaration of Helsinki.

The wound healing rate was analyzed retrospectively, based on the results of routine measurements of wound area, performed within at least 1 month preceding the assessment. The measurements were done using Visitrak Digital device (Smith\&Nephew, Largo, FL, USA) in weekly intervals. The results were used to calculate the percent reduction of an initial wound surface, expressed then as mean wound healing rate per week (Cardinal et al. 2008). To allow easier patients comparison, the mean healing rate below $5 \%$ per week was arbitrarily considered as poor, $5-10 \%$ (moderate), and 11-15\% (good), whereas the mean healing rate above $15 \%$ per week was identified as fast. 
The serum levels of 25-hydroxy vitamin $\mathrm{D}_{3}, 25(\mathrm{OH}) \mathrm{D}_{3}$, were measured using the Vitamin D ELISA Kit (Cayman Chemicals, Ann Arbor, MI, USA) with the assay detection limit of $0.19 \mathrm{ng} / \mathrm{ml}$. To reduce the influence of differential sun exposure on vitamin D level (Martineau et al. 2011), the study was conducted between October and March.

The levels of LL-37 in serum samples were determined using the Human LL-37 ELISA Kit (MyBioSource, San Diego, CA, USA). The test detection range was $1.56-100 \mathrm{ng} / \mathrm{ml}$.

The cytokine levels in serum samples were measured in duplicates, using Human IL-6, IL-8, and TNF Ultrasensitive ELISA kits, respectively, according to detailed protocols provided by the manufacturer (all tests from Invitrogen, Camarillo, CA, USA). The absorbance of analyzed samples was estimated using the Microplate Reader 550 (BIO-RAD, Hercules, CA, USA). Based on the respective standard calibration curves, the OD results were converted to the specific cytokine concentrations (expressed in $\mathrm{pg} / \mathrm{ml}$ ). For all the tested cytokines, the assays sensitivity, corresponding to the lowest points of the standard calibration curves, was $0.4 \mathrm{pg} / \mathrm{ml}$.

The data were calculated using the BrightStat online software (Stricker 2008).

\section{Results}

The clinical characteristics of patients group were shortly summarized in Table 1.

The mean healing rate below $5 \%$ per week, which was considered as poor, was observed in six patients, whereas the mean healing rate above $15 \%$ per week, described as fast, was found in five individuals. The moderate and good healing rates were observed in six and two patients, respectively (Fig. 1).

Table 1 Summary of clinical data

\begin{tabular}{ll}
\hline Feature/parameter & Value \\
\hline Age (years \pm SD) & $68.6 \pm 13.8$ \\
Sex (female/male) & $12 / 7$ \\
Venous insufficiency in: & - \\
$\quad$ Superficial system & 19 \\
Deep system & 12 \\
Mean wound size at the beginning & $59.6 \mathrm{~cm}^{2}(8.0-190.0)$ \\
$\quad$ of observation period (min/max) & \\
Mean healing rate $(\%$ per week) & $9.7 \pm 6.6$ \\
Poor & $3.5 \pm 0.5$ \\
Moderate & $6.8 \pm 1.0$ \\
Good & $13.0 \pm 1.4$ \\
Fast & $19.2 \pm 2.2$ \\
\hline
\end{tabular}

The concentrations of $25(\mathrm{OH}) \mathrm{D}_{3}$ in tested serum samples ranged from 4-29 ng/ml, with a mean value $18.2 \pm 7.1 \mathrm{ng} / \mathrm{ml}$. It did not show any correlation with the mean healing rate observed in analyzed patients (Fig. 2).

The mean serum level of LL-37 was $12.2 \pm 11.1 \mathrm{ng} / \mathrm{ml}$, with range $0.1-37.6 \mathrm{ng} / \mathrm{ml}$. Interestingly, serum levels of LL-37 did not reveal statistically significant correlation with serum concentrations of $25(\mathrm{OH}) \mathrm{D}_{3}$ metabolite (Fig. 3). On the other hand, serum concentrations of LL-37 were strongly associated with calculated mean healing rates. Thus, the lowest serum levels of LL-37 were found in patients with poor (mean $2.6 \pm 2.2 \mathrm{ng} / \mathrm{ml}$ ) and moderate wound healing (mean $9.8 \pm 7.6 \mathrm{ng} / \mathrm{ml}$ ), whereas higher values of LL-37 were observed in patients with good and fast healing rates (mean $17.7 \pm 7.3 \mathrm{ng} / \mathrm{ml}$ and $26.6 \pm 7.2 \mathrm{ng} / \mathrm{ml}$, respectively) (Fig. 4).

The mean serum levels of tested pro-inflammatory cytokines were: $3.5 \pm 2.9 \mathrm{pg} / \mathrm{ml}$ for IL- $6,6.3 \pm 5.6 \mathrm{pg} / \mathrm{ml}$ for IL-8, and $10.6 \pm 2.5 \mathrm{pg} / \mathrm{ml}$ for TNF. Although slight associations were observed between all the tested cytokines, as well as between IL- 6 or IL- 8 and $25(\mathrm{OH})$ vitamin D metabolite, none of observed trends reached statistical significance.

\section{Discussion}

The results of our proof of concept study support other reports showing that vitamin D deficiency is the common issue, particularly in elderly population. Noteworthy, when considering $30 \mathrm{ng} / \mathrm{ml}$ of $25(\mathrm{OH}) \mathrm{D}_{3}$ as the lowest sufficient serum level (Holick et al. 2011), none of tested individuals from our study group reached normal value. This observation may be clinically relevant, especially in context of widely discussed various non-skeletal activities of vitamin $\mathrm{D}$, including the modulation of immune response or tissue regeneration (Gunville et al. 2013; Hewison 2012; LópezLópez et al. 2014; McKenna et al. 2015; Ross et al. 2011; Trochoutsou et al. 2015). However, in our vitamin D-deficient patients, we did not observe any association between serum levels of $25(\mathrm{OH}) \mathrm{D}_{3}$ and wound healing rates. The lack of such association may suggest that the postulated role of vitamin D in chronic wound healing, if any, is rather indirect and should be considered as a component of more complex mechanisms.

One of hypothetical mechanisms may concern previously mentioned the involvement of vitamin $\mathrm{D}$ in the regulation of promoter activity and the expression of human cathelicidin LL-37 (Dixon et al. 2012). However, we did not find any correlation between serum levels of $25(\mathrm{OH}) \mathrm{D}_{3}$ and LL-37. Interestingly, similar lack of correlation between serum levels of $25(\mathrm{OH}) \mathrm{D}_{3}$ and LL-37 was also observed in another study, in patients with active 
Fig. 1 Examples of paired wound pictures representative for various healing patterns: a, b poor; c, $\mathbf{d}$ moderate; $\mathbf{e}, \mathbf{f}$ good; and $\mathbf{g}, \mathbf{h}$ fast healing. The pictures in left column (a, c, e, and g) show the wound at the beginning of observation period (day 0 ), whereas the pictures in right column (b, $\mathbf{d}, \mathbf{f}$, or $\mathbf{h}$, respectively) show the same wounds after 4 weeks of standard treatment
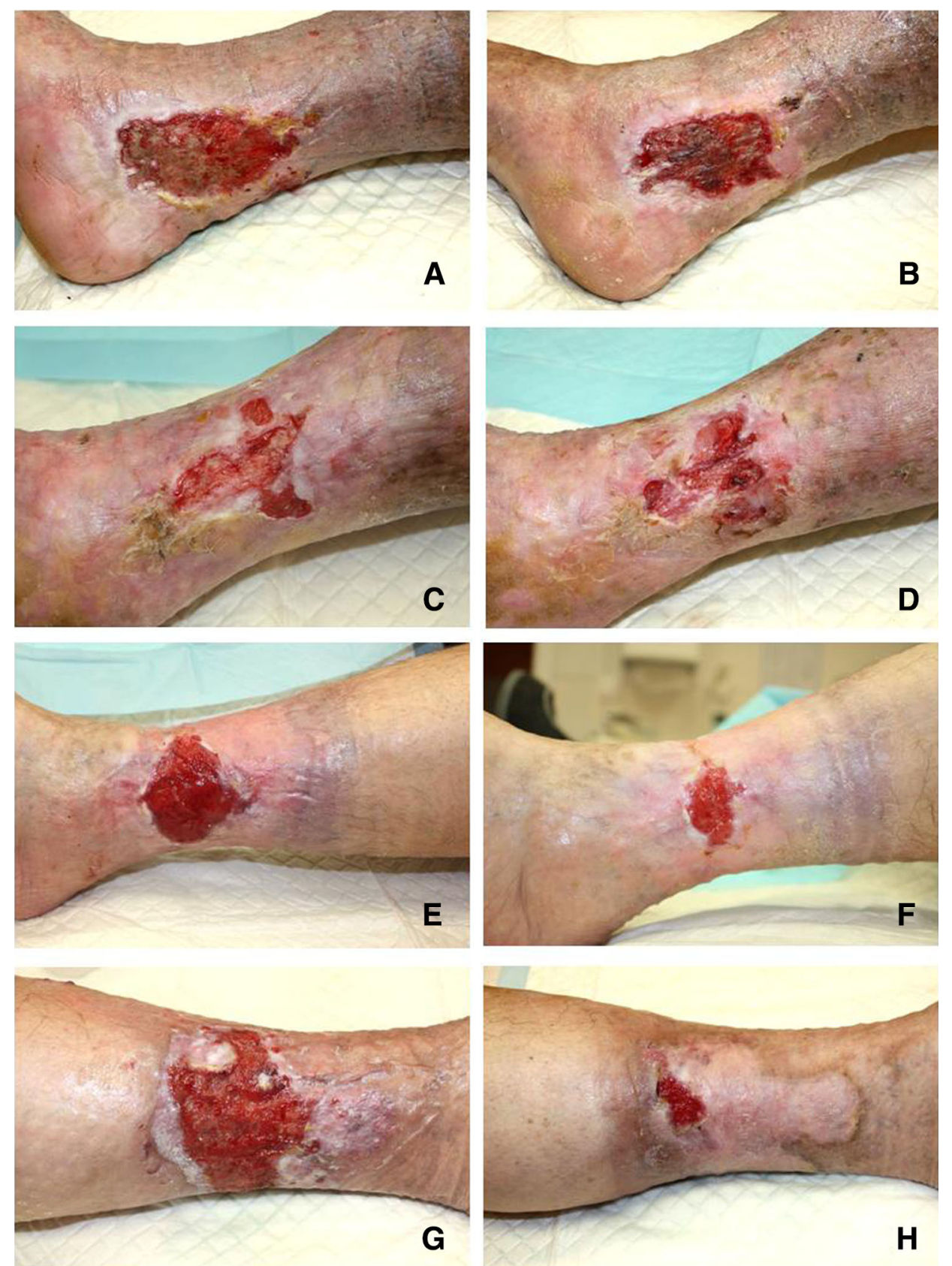

tuberculosis (Yamshchikov et al. 2010). Possibly, such discrepancy may be due to different metabolites of vitamin $\mathrm{D}$, analyzed in mentioned studies. The authors of previously mentioned report have tested $1,25(\mathrm{OH}) \mathrm{D}_{3}$, whereas we have assessed serum levels of $25(\mathrm{OH}) \mathrm{D}_{3}$. On the other hand, although 1,25-hydroxy $\mathrm{D}_{3}$ represents active form of this vitamin, in patients without clinically overt kidney insufficiency, the level of $25(\mathrm{OH}) \mathrm{D}_{3}$ may also be used as the good indicator of vitamin D deficiency (Holick et al. 2011; Ross et al. 2011). One has to keep in mind that the lack of association may also result from small number of patients, too small, to find any statistically significant correlation. However, even despite very small group, we have observed considerable association between serum concentrations of LL-37 and mean wound healing rates. The observed difference did not correlate with serum levels of selected pro-inflammatory cytokines (IL-6, IL-8, or TNF). Moreover, those levels did not differ among patients groups, thus suggesting that, possibly, at least in our observation, LL-37 levels and healing rates may represent rather individual patient properties, than actual inflammatory status of the wound.

Noticeably, the serum concentrations of LL-37 may differ from those in wound fluid, e.g., as the result of its 


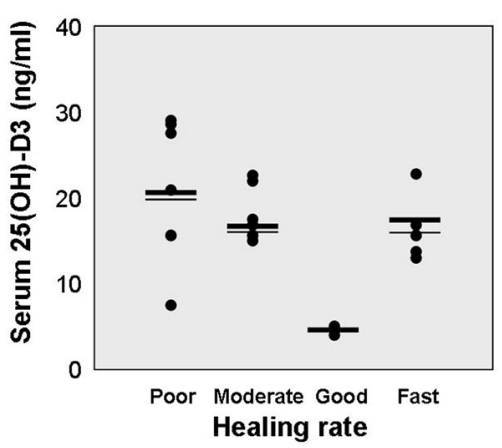

Fig. 2 Serum concentration of 25-hydroxy-vitamin D (ng/ml) in relation to wound healing rates. Each dot represents data of one patient. Bold lines correspond to mean value, whereas thin lines represent median for respective groups

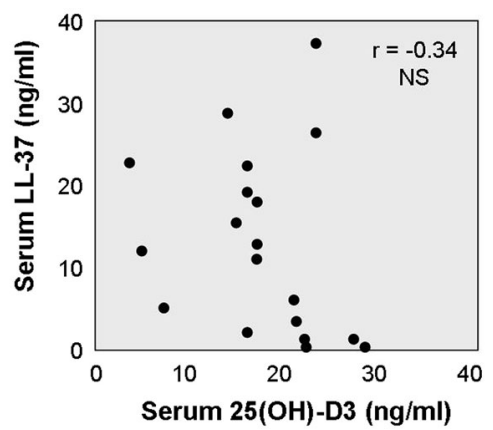

Fig. 3 Association between serum levels of 25-hydroxy-vitamin D $(\mathrm{ng} / \mathrm{ml})$ and human LL-37 (ng/ml). Each dot represents data of one patient. NS non-significant

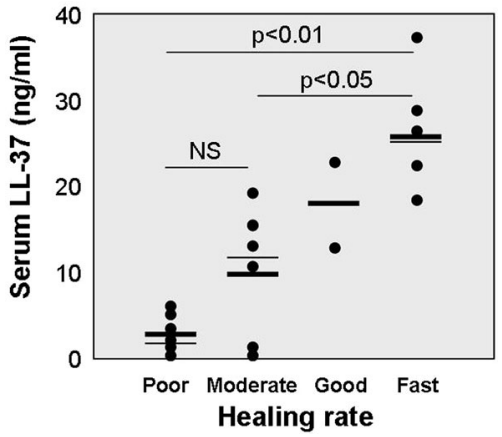

Fig. 4 Serum concentration of LL-37 (ng/ml) in relation to wound healing rates. Each dot represents the data of one patient. Bold lines correspond to mean values, whereas thin lines represent median for respective groups. Statistical significance was calculated using MannWhitney $U$ test

extensive local production (Heilborn et al. 2010). Therefore, if available, exudates should obviously be considered as the better material for studies focused on the wound healing. Regrettably, exudates collection in some patients, especially with small wounds, or with less exudate amounts, may be impossible, or at least very difficult (Cutting 2003). On the other hand, the overall concentration of biologically active factors in the serum strongly determines the composition of wound exudates (Forsberg et al. 2008). To verify, whether serum levels of LL-37 correspond to those in wound exudates, we have compared both the types of samples in eight patients from our small study group. We have found that the concentrations of LL-37 in all the tested exudates were even up to tenfold higher, as compared to respective serum samples. However, even despite different nominal values, the LL-37 levels in wound exudates reflected those observed in serum samples. Hence, low serum levels corresponded to lower concentration in exudate samples, whereas high levels of LL-37 in exudates were observed in patients with its higher concentrations in serum (data not shown). Noteworthy, as already mentioned, high levels of LL-37 in serum and/or wound fluid were associated with faster wound healing. On the other hand, low concentrations of LL-37 in serum (and, presumably, in wound exudates) correlated with poor and slow healing rate.

When considering postulated pleiotropic action of LL37 in pathophysiology of chronic wounds (Dressel et al. 2010; Heilborn et al. 2003), the assessment of endogenous LL-37 concentration in serum or, if available, in wound exudates, may be useful to predict the expected healing efficacy. On the other hand, our data provide the rationale for use of exogenous LL-37 in treatment of chronic wounds. Indeed, recently, Grönberg et al. (2014) have shown that the topical application of 0.5 or $1.6 \mathrm{mg} / \mathrm{ml}$ of human recombinant LL-37 significantly accelerated reduction of wound surface in patients with venous leg ulcer. Interestingly, the authors of that study have found that the best clinical effect was limited to low and mid doses of LL-37, whereas a dose of $3.2 \mathrm{mg} / \mathrm{ml}$ appeared to be less effective. Moreover, such a high dose was associated with increased risk of adverse reaction (ulcer necrosis, or severe inflammatory reaction). Possibly, the measurement of serum LL-37 levels would enable the selection of patients, who especially benefit from local application of this factor. According to that we hypothesize, that in patients with high endogenous levels of LL37, we could expect good healing efficacy using the standard therapy only, whereas individuals with low endogenous LL-37 could be good candidates for topical wound treatment with recombinant LL-37. Nevertheless, due to small patients group, this issue still requires further studies.

Acknowledgments The study was supported by the individual research Grant No. 1M15/NM2/15 of the Medical University of Warsaw.

\section{Compliance with ethical standards}

Conflict of interest All authors declare no conflict of interest. 
Open Access This article is distributed under the terms of the Creative Commons Attribution 4.0 International License (http:// creativecommons.org/licenses/by/4.0/), which permits unrestricted use, distribution, and reproduction in any medium, provided you give appropriate credit to the original author(s) and the source, provide a link to the Creative Commons license, and indicate if changes were made.

\section{References}

Agier J, Efenberger M, Brzezińska-Błaszczyk E (2015) Cathelicidin impact on inflammatory cells. Cent Eur J Immunol 40:225-235

Ammons MC (2010) Anti-biofilm strategies and the need for innovations in wound care. Recent Pat Antiinfect Drug Discov 5:10-17

Banerjee J, Sen CK (2015) MicroRNA and wound healing. Adv Exp Med Biol 888:291-305

Barlow PG, Svoboda P, Mackellar A et al (2011) Antiviral activity and increased host defense against influenza infection elicited by the human cathelicidin LL-37. PLoS One 6:e25333

Burkiewicz CJ, Guadagnin FA, Skare TL et al (2012a) Vitamin D and skin repair: a prospective, double-blind and placebo controlled study in the healing of leg ulcers. Rev Col Bras Cir 39:401-407

Burkiewicz CJ, Skare TL, Malafaia O et al (2012b) Vitamin D deficiency in patients with chronic venous ulcers. Rev Col Bras Cir 39:60-63

Cardinal M, Eisenbud DE, Phillips T et al (2008) Early healing rates and wound area measurements are reliable predictors of later complete wound closure. Wound Repair Regen 16:19-22

Cutting KF (2003) Wound exudate: composition and functions. Br J Community Nurs 8(9 Suppl):4-9

Dixon BM, Barker T, McKinnon T et al (2012) Positive correlation between circulating cathelicidin antimicrobial peptide (hCAP18/ LL-37) and 25-hydroxyvitamin D levels in healthy adults. BMC Res Notes 5:575

Doss M, White MR, Tecle T et al (2010) Human defensins and LL-37 in mucosal immunity. J Leukoc Biol 87:79-92

Dressel S, Harder J, Cordes J et al (2010) Differential expression of antimicrobial peptides in margins of chronic wounds. Exp Dermatol 19:628-632

Forsberg JA, Elster EA, Andersen RC et al (2008) Correlation of procalcitonin and cytokine expression with dehiscence of wartime extremity wounds. J Bone Joint Surg Am 90:580-588

Gombart AF (2009) The vitamin D-antimicrobial peptide pathway and its role in protection against infection. Future Microbiol 4:1151-1165

Gombart AF, Borregaard N, Koeffler HP (2005) Human cathelicidin antimicrobial peptide (CAMP) gene is a direct target of the vitamin $\mathrm{D}$ receptor and is strongly up-regulated in myeloid cells by 1,25-dihydroxyvitamin D3. FASEB J 19:1067-1077

Gonzalez-Curiel I, Trujillo V, Montoya-Rosales A et al (2014) 1,25dihydroxyvitamin D3 induces LL-37 and HBD-2 production in keratinocytes from diabetic foot ulcers promoting wound healing: an in vitro model. PLoS One 9:e111355

Grönberg A, Mahlapuu M, Ståhle M et al (2014) Treatment with LL37 is safe and effective in enhancing healing of hard-to-heal venous leg ulcers: a randomized, placebo-controlled clinical trial. Wound Repair Regen 22:613-621

Grzela K, Zagórska W, Grzela T (2012) Mechanisms of the innate immunity in the respiratory system. Cent Eur J Immunol 37:280-285

Gunville CF, Mourani PM, Ginde AA (2013) The role of vitamin D in prevention and treatment of infection. Inflamm Allergy Drug Targets 12:239-245
Heilborn JD, Nilsson MF, Kratz G et al (2003) The cathelicidin antimicrobial peptide LL-37 is involved in re-epithelialization of human skin wounds and is lacking in chronic ulcer epithelium. J Invest Dermatol 120:379-389

Heilborn JD, Weber G, Grönberg A et al (2010) Topical treatment with the vitamin D analogue calcipotriol enhances the upregulation of the antimicrobial protein hCAP18/LL-37 during wounding in human skin in vivo. Exp Dermatol 19:332-338

Hewison M (2012) Vitamin D and the immune system: new perspectives on an old theme. Rheum Dis Clin N Am 38:125-139

Holick MF, Binkley NC, Bischoff-Ferrari HA et al (2011) Evaluation, treatment, and prevention of vitamin D deficiency: an Endocrine Society clinical practice guideline. J Clin Endocrinol Metab 96:1911-1930

Houston DK, Tooze JA, Demons JL et al (2015) Delivery of a vitamin $\mathrm{D}$ intervention in homebound older adults using a meals-onwheels program: a pilot study. J Am Geriatr Soc 63:1861-1867

Jawień A, Szewczyk MT, Kaszuba A et al (2011) Guidelines for the management of chronic venous leg ulceration. Recommendations of a multidisciplinary expert group. Leczenie Ran 8:59-80

Koczulla R, von Degenfeld G, Kupatt C et al (2003) An angiogenic role for the human peptide antibiotic LL-37/hCAP-18. J Clin Invest 111:1665-1672

Krejner A, Grzela T (2015) Modulation of matrix metalloproteinases MMP-2 and MMP-9 activity by hydrofiber-foam hybrid dressing-relevant support in the treatment of chronic wounds. Cent Eur J Immunol 40:391-394

Litwiniuk M, Grzela T, Brawura-Biskupski-Samaha R (2009) Chronic inflammation in venous leg ulcer-problems and perspectives. Cent Eur J Immunol 34:247-251

López-López N, González-Curiel I, Treviño-Santa Cruz MB et al (2014) Expression and vitamin D-mediated regulation of matrix metalloproteinases (MMPs) and tissue inhibitors of metalloproteinases (TIMPs) in healthy skin and in diabetic foot ulcers. Arch Dermatol Res 306:809-821

Martineau AR, Nhamoyebonde S, Oni T et al (2011) Reciprocal seasonal variation in vitamin D status and tuberculosis notifications in Cape Town, South Africa. Proc Natl Acad Sci USA 108:19013-19017

McKenna MJ, Murray BF, O'Keane M et al (2015) Rising trend in vitamin D status from 1993 to 2013: dual concerns for the future. Endocr Connect 4:163-171

Mustoe TA, O'Shaughnessy K, Kloeters O (2006) Chronic wound pathogenesis and current treatment strategies: a unifying hypothesis. Plast Reconstr Surg 117(Suppl 7):S35-S41

Overhage J, Campisano A, Bains M et al (2008) Human host defense peptide LL-37 prevents bacterial biofilm formation. Infect Immun 76:4176-4182

Partsch H, Mortimer P (2015) Compression for leg wounds. Br J Dermatol 173:359-369

Ross AC, Taylor CL, Yaktine AL et al (2011) Institute of Medicine (US) Committee to review dietary reference intakes for vitamin $\mathrm{D}$ and calcium. Dietary reference intakes for calcium and vitamin D. National Academies Press, Washington, DC

Shaw T, Martin P (2009) Epigenetic reprogramming during wound healing: loss of polycomb-mediated silencing may enable upregulation of repair genes. EMBO Rep 10:881-886

Stricker D (2008) BrightStat.com: free statistics online. Comput Methods Programs Biomed 92:135-143

Tiwari S, Pratyush DD, Gupta SK et al (2014) Vitamin D deficiency is associated with inflammatory cytokine concentrations in patients with diabetic foot infection. Br J Nutr 112:1938-1943

Trochoutsou AI, Kloukina V, Samitas K et al (2015) Vitamin-D in the immune system: genomic and non-genomic actions. Mini Rev Med Chem 15:953-963 
Vandamme D, Landuyt B, Luyten W et al (2012) A comprehensive summary of LL-37, the factotum human cathelicidin peptide. Cell Immunol 280:22-35

Waring MJ, Parsons D (2001) Physico-chemical characterisation of carboxymethylated spun cellulose fibres. Biomaterials 22:903-912

Weinstein AL, Lalezarzadeh FD, Soares MA et al (2015) Normalizing dysfunctional purine metabolism accelerates diabetic wound healing. Wound Repair Regen 23:14-21

Wong JH, Ng TB, Legowska A (2011) Antifungal action of human cathelicidin fragment (LL13-37) on Candida albicans. Peptides 32:1996-2002
Wuerth K, Hancock RE (2011) New insights into cathelicidin modulation of adaptive immunity. Eur J Immunol 41:2817-2819

Yamshchikov AV, Kurbatova EV, Kumari M et al (2010) Vitamin D status and antimicrobial peptide cathelicidin (LL-37) concentrations in patients with active pulmonary tuberculosis. Am J Clin Nutr 92:603-611

Zubair M, Malik A, Meerza D et al (2013) 25-Hydroxyvitamin D [25(OH)D] levels and diabetic foot ulcer: is there any relationship? Diabetes Metab Syndr 7:148-153 